\title{
Acute adult-onset still's disease presenting as pulmonary hemorrhage, urticaria, angioedema and leukemoid reaction: a case report and literature review
}

\author{
Sergio A Mora Alfonso ${ }^{1}$, Daniel M Cuestas Rodríguez ${ }^{1,2,6^{*}}$, John D Londoño ${ }^{3}$, Rafael Valle-Oñate ${ }^{4}$
} and Gerardo Quintana ${ }^{5}$

\begin{abstract}
Introduction: Adult-onset Still's disease is a rare systemic inflammatory disorder of unknown aetiology characterized by the classic triad of persistent high spiking fevers, joint pain and a distinctive salmon-colored bumpy rash however, the multiorgan involvement can be present.

Case description: A 40-year-old woman previously healthy was referred to our hospital with 7 days of high fever and generalized arthralgia, The physical exam revealed angioneurotic edema detected on soles, palms and tongue and widespread red, urticated plaques in a symmetrical distribution affecting the arms, dorsal hands, upper and lower chest and back. Followed 5 days later by fever, the patient presented dyspnea, cough and hypoxemia, the imaging studies showed unilateral consolidation and pleural effusion. The bronchoscopy with bronchoalveolar lavage and skin biopsy were consistent with neutrophilic urticarial. The hematological disorders, infections and other autoimmune diseases were excluded.
\end{abstract}

Discussion and evaluation: The diagnosis of adult-onset Still's disease can be very difficult. There are no specific tests and reliance is usually placed on a symptom complex and the well described typical rash seen in most patients. In recent years, however, other cutaneous manifestations of Adult-onset Still's disease have been reported but these are not so well known.

Conclusions: The evidence of rare manifestations is growing and the early clinical presentation of Adult-onset Still's is extremely variable, making diagnosis difficult. For this reason, data on early clinical presentation of the disease are of interest. We reported the first case of acute Adult-onset Still's disease with the association of pulmonary hemorrhage, urticaria and angioedema including a rare systemic manifestation as leukemoid reaction.

Keywords: Adult-onset still's disease; Urticaria; Angioedema; Leukemoid reaction; Pulmonary hemorrhage

\section{Background}

Adult-onset Still's disease (AOSD) is a systemic inflammatory disorder of unknown etiology and pathogenesis with a high range of manifestations to represents a diagnostic and therapeutic challenge (Bywaters 1971). The usual clinical features are spiking fever, arthritis, macular

\footnotetext{
* Correspondence: daniel00515@hotmail.com

${ }^{1}$ Rheumatology Unit, Department of Internal Medicine, Hospital Universitario De La Samaritana E.S.E, Bogotá, Colombia

${ }^{2}$ Rheumatology Unit, Department of Internal Medicine, Universidad de La Sabana, Hospital Universitario de La Samaritana E.S.E, Bogotá, Colombia Full list of author information is available at the end of the article
}

or maculopapular rash, sore throat, myalgias, lymphadenopathy and splenomegaly (Kadar and Petrovicz 2004). The diagnosis of AOSD can be very complex because there are no specific tests and reliance is usually placed on a symptom complex and the well described typical rash seen in most patients. In recent years, the evidence of rare manifestations is growing and the early clinical presentation of AOSD is extremely variable, making diagnosis difficult. For this reason, data on early clinical presentation of the disease are of interest. 
We present a rare case with many unusual manifestations. As far as we know this is the second case reported before of AOSD with an initial presentation as urticaria and angioedema (Soy 2004) and the first case of acute AOSD that reported the association with pulmonary hemorrhage and leukemoid reaction (LR). We suggest to the clinicians to keep in mind these findings and emphasize the need to consider urticaria and angioedema in the differential diagnosis of cutaneous manifestations of AOSD and recognize this new finding of pulmonary hemorrhage as another possibility in the differential diagnosis of infiltrates in acute AOSD.

\section{Case description}

A 40-year-old woman, previously healthy, Colombian, was admitted to the Department of Rheumatology at Hospital Militar Central, with a fever of 39 C, generalised arthralgia involving the elbows, wrists, proximal and distal interphalangeal joints, metacarpophalangeal and metatarsophalangeal joints, knees and ankles, and fatigue. She had been in her usual state of good health until 2 weeks before admission and these symptoms starting shortly after the patient had a sore throat for 7 days.

Examination revealed angioneurotic edema detected on soles, palms and tongue (Figure 1a) and widespread red, urticated plaques in a symmetrical distribution affecting the arms, dorsal hands, upper and lower chest and back (Figure 1b). The rest of the examination was unremarkable. These lesions were present for less than $10 \mathrm{~h}$ per day and were not more pronounced at night with no associated bruising. She was diagnosed as having infection-associated-urticaria in a peripheral hospital and was treated with antibiotics (ciprofloxacin) and antihistamines (loratadine) without diminishment of her symptoms. Followed 5 days later by fever, the patient presented dyspnea, cough and hypoxemia. A chest x-ray film showed a patchy right lower lobe infiltrate (Figure 2a) and computed tomography showed unilateral consolidation and pleural effusion (Figure 2b).
An early bronchoscopy with bronchoalveolar lavage was indicated revealing hemorrhagic lavage and pathological examination showed hemosiderin-containing macrophages in $80 \%$. Bronchoalveolar lavage specimen was sent for routine bacterial cultures, fungal, viral and Pneumocystis carinii; all of the results were negative. A skin biopsy demonstrated dermal oedema, and a marked perivascular and neutrophilic infiltrate with no evidence of structural vasculitis. These features were consistent with neutrophilic urticaria (Figure 3). Other investigations revealed a normocytic anaemia $\mathrm{Hb} 11.5 \mathrm{~g} / \mathrm{dL}$ erythrocyte mean corpuscolar volume $86 \mathrm{fl}$ platelet count $408.000 / \mathrm{mm}^{3}$, a marked white blood cell count (WBC) $67.200 \mathrm{~mm}^{3}$ with 91\% neutrophils, 5\% lymphocytes, $1 \%$ eosinophils, $3 \%$ monocytes and markedly elevated acute phase reactants: erythrocyte sedimentation rate $49 \mathrm{~mm}$ in the first hour, C-reactive protein 11,43 $\mathrm{mg} / \mathrm{dl}$ and ferritin $1650 \mu \mathrm{g} / \mathrm{L}$, alanine aminotransferase was mildly elevated at $74 \mathrm{IU} / \mathrm{L}$, lactate dehydrogenase $1200 \mathrm{IU} / \mathrm{L}$ and serum albumin reduced at 3,4 g/L. Antinuclear antibodies (immunofluorescence-Hep-2 cells), rheumatoid factor (nephelometry), antistreptolysin $\mathrm{O}$, cold agglutinins, cryoglobulins and serum electrophoresis were unremarkable. There was no serological evidence for active or recent infection with the following organisms: Toxoplasma gondii, group B streptococci, hepatitis A, B or C, HIV, cytomegalovirus, tuberculosis and syphilis. Blood cultures were negative. Ultrasound investigation of the liver and biliary tract was normal. In the bone marrow aspiration, we found remarkable hyperplasia and granulocytes of each mature state, without an increase of myeloblasts, the neutrophil alkaline phosphatase score was high, $\mathrm{Ph}$ chromose was negative. Immunophenotyping showed mature neutrophils expressing surface antigens $\mathrm{CD} 13$ and $\mathrm{CD} 15$ at a level higher than 95\% and negative for CD34 and HLA-DR.

She was diagnosed with AOSD and methylprednisolone (mini-boluses of $125 \mathrm{mg} /$ day per 3 days) was initiated as prednisone sparing therapy. The patient's pulmonary

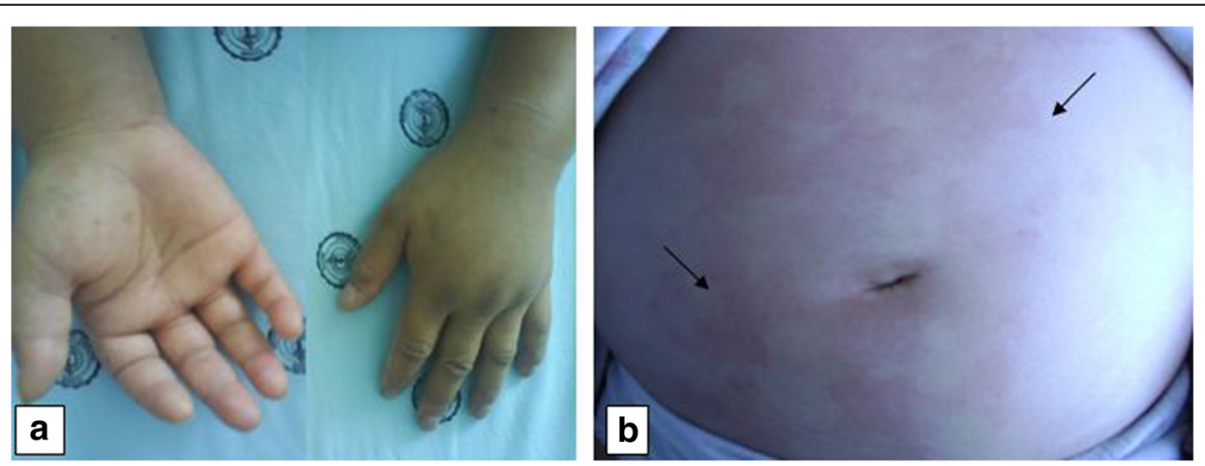

Figure 1 Unusual clinical findings of AOSD in skin and hands. A photography of dorsal and palms aspect of hands shows marked angioedema (a). The urticarial eruption is evident in the abdominal photography and shows the red and urticated plaques (black arrows) (b). 

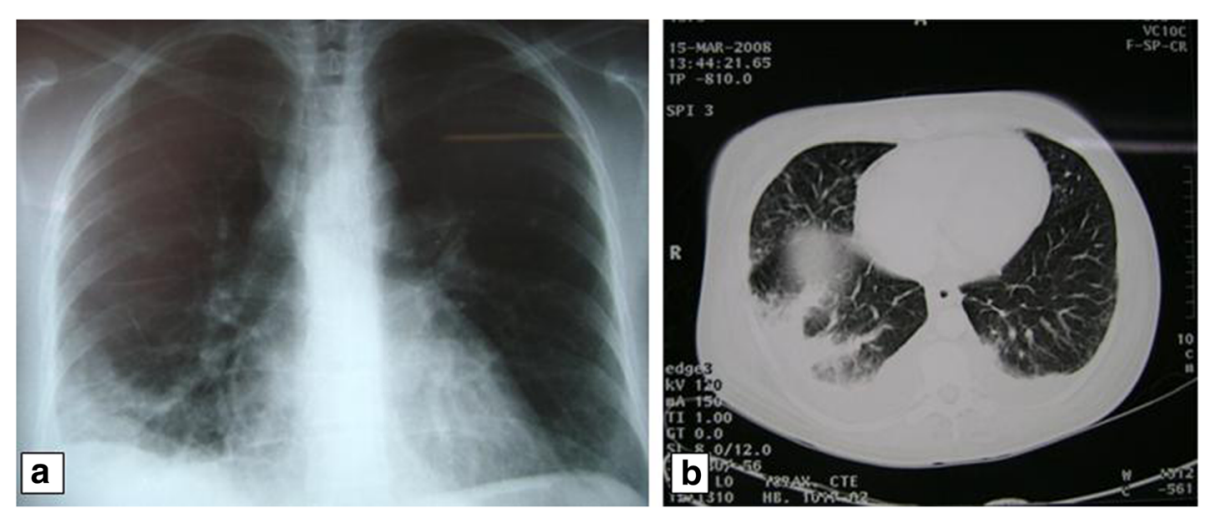

Figure 2 Unusual Paraclinical findings of AOSD in lung. A chest radiograph shows a patchy right lobe consolidation in the lower lung zone (a). CT image shows extensive areas of airspace consolidation due to alveolar hemorrhage in right lung. The bilateral pleural effusions are also notable (b).

symptoms improved with the doses of pulsed corticosteroids. After 3 days of pulsed methylprednisolone, therapy was maintained with $0.5 \mathrm{mg} / \mathrm{kg}$ of prednisone orally. Treatment with NSAIDs and prednisone controlled the rash, fever, arthritis, angioedema and significantly reduced the serum ferritin levels and all markers of activity disease. Two weeks after the pulse treatment, the chest radiography became normal. Methotrexate was prescribed for long term control of the disease at a dose of 7,5 mg/week. One month later prednisone was slowly decreased to $12,5 \mathrm{mg} /$ day and withdrawn over three months. No activation period was observed during the one-year follow-up period.

\section{Discussion and evaluation}

First described by (Bywaters 1971), AOSD has no single diagnostic test; rather, the diagnosis is based upon clinical criteria such as arthralgia, fever, skin rash, lymphadenopathy, and hepatosplenomegaly (Kadar and Petrovicz 2004). It is not uncommon for AOSD to involve other organs, such as the liver, kidney, bone marrow and, less often, the lungs. Unlike other rheumatic diseases with multiorgan involvement, in which respiratory abnormalities are well studied and documented (eg, rheumatoid arthritis, systemic lupus erythematosus, and systemic sclerosis).The pulmonary manifestations of AOSD include pleural effusion uni or bilateral (5 to 31\%) or transient pulmonary infiltrates (Cheema and Quismorio 1999; Kozel and Sabroe 2004; Crispin et al. 2005), acute and chronic pneumonitis (Kadar and Petrovicz 2004), functional abnormalities and miscellaneous conditions, such as diaphragmatic dysfunction, drug-induced lung disease and respiratory distress syndrome (Cheema and Quismorio 1999). However, to the best of our knowledge, pulmonary haemorrhage in acute presentation of AOSD has not been reported before and the previous case of Sari et al (Sari et al 2009), described the first case of chronic presentation of AOSD complicated with diffuse alveolar haemorrhage during the acute flare of the disease.

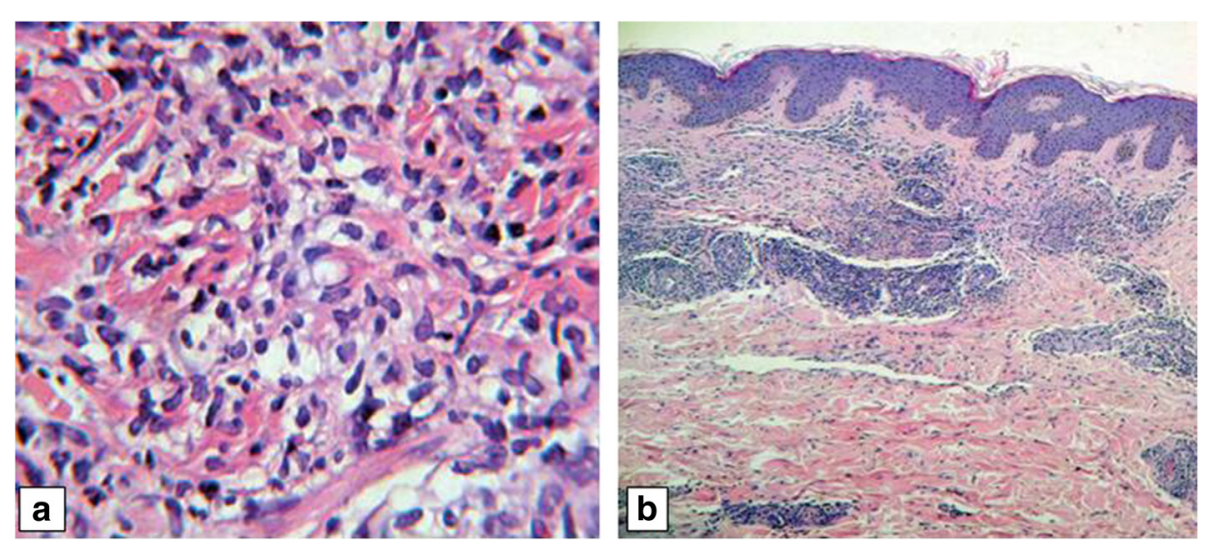

Figure 3 Abdominal skin biopsy with haematoxylin-eosin-stained. Perivascular and interstitial infiltrate composed mainly of neutrophils on upper and middle dermis with original magnification $\times 20$ (a). Shows the same specimen in more detail with original magnification $\times 100$ (b). 
The typical rash is a transient salmon-pink rash that flares during febrile episodes and is absent or minimal when the patient is afebrile. Histologic features comprised of a superficial perivascular lymphocytic infiltrate with scattered neutrophils. An eruption consisting of persistent papules and plaques has been reported frequently and is now estimated to be present in up to $65 \%$ of AOSD patients (Lee et al. 2005). This latter eruption is pruritic and often has a linear configuration, thought to be due to a Koebnerization phenomenon. However, there are an increasing number of reports of atypical cutaneous findings in AOSD, including persistent plaques and linear pigmentation, eczematous lesions, urticaria and angioedema, vesiculopustules on the hands and feet, erythema chronicum migrans, persistent generalized erythema, generalized peau d'orange-like skin infiltration (diffuse cutaneous mucinosis), acne-like lesions, noncaseating dermal granulomas, eczematous lesions and toxic eruptions (Affleck 2005).

Early diagnosis of AOSD remains a challenge to the clinicians. Physicians may not consider AOSD in the absence of the typical rash due to its apparently relative high accuracy (Masson et al 1996); however, due to the increasing number of reports of atypical cutaneous findings in AOSD with multiple morphologies, the presence of these features may be important in the diagnosis and could be incorporated into the diagnostic criteria. Urticarial rash has rarely been observed in AOSD. On reviewing the literature, Setterfield et al. (Setterfield et al. 1998) described the first case of chronic urticaria associated with AOSD presenting 9 months before the onset of the systemic signs of classic AOSD; since then many other cases have been described and including the latter, the description of urticaria in AOSD has been made in eight (8) case reports in the English literature (Affleck 2005; Setterfield et al 1998; Salaffi et al. 2009; Gesierich et al. 2009: Criado et al. 2006; Koning et al. 2007; Zendee et al. 2004) and these include the findings in five adolescent patients that indicated a disorder indistinguishable from AOSD, but not diagnosable as Systemic Juvenile Idiopathic Arthritis (SJIA) (Prendiville et al.2004). The presented case described both signs of urticaria and angioneurotic edema that preceded the fever and other symptoms and demonstrated histologic features of perivascular inflammatory infiltrate of the superficial dermis, composed of neutrophils and devoid vasculitis. The presence of urticaria with these histological features, can be a presenting manifestation useful in early recognition of AOSD. To the best of our knowledge, this is the second case of AOSD who presented with the combination of angioneurotic edema and urticaria in the acute phase of the disease (Soy 2004).

The evaluation of a patient with recurrent fever, urticaria and arthritis as our patient initial clinical signs should also include tests to exclude hematological, infectious, and autoimmune diseases (Table 1), eg, a complete blood count, blood cultures, serology for hepatitis, and streptococcal antibodies, tests for rheumatoid factor, antinuclear antibodies, cold agglutinins, cryoglobulins, and ferritin.

In AOSD common haematological abnormalities include leucocytosis, which often accompanies increased disease activity, anaemia, and thrombocytosis (Pouchot

Table 1 Summary of the differential diagnosis of urticaria, arthritis and fever from the literature

\begin{tabular}{ll}
\hline $\begin{array}{l}\text { Classes of } \\
\text { diseases }\end{array}$ & Diseases \\
\hline $\begin{array}{l}\text { Hereditary } \\
\text { auto-inflammatory } \\
\text { syndromes }\end{array}$ & Familial cold urticaria \\
\end{tabular}

syndromes

Cryopyrin-associated syndrome

Muckle-Wells syndrome

Familial cold urticaria

Chronic infantile neurologic cutaneous and articular syndrome (CINCA/NOMID)

Infectious

Hepatitis B, C

diseases

Chronic meningococcemia

STAR complex (Sore Throat, Arthritis and Rash secondary to a viral infection)

Streptococcal pharyngitis with reactive arthralgia and exanthem

$\begin{array}{ll}\begin{array}{l}\text { Autoimmune } \\ \text { disorders }\end{array} & \text { AOSD } \\ & \text { Systemic lupus erythematosus } \\ & \text { Acquired C1 esterase deficiency } \\ & \text { Schnitzler syndrome } \\ \text { Hematological } & \text { Lymphoma } \\ \text { disorders } & \text { Monoclonal gammopathy of unknown } \\ & \text { significance } \\ & \text { Multiple myeloma } \\ & \text { Polyneuropathy, organomegaly, endocrinopathy, } \\ & \text { monoclonal gammopathy, and skin changes } \\ & \text { (POEMS) syndrome } \\ & \text { Waldenström's macroglobulinemia } \\ & \text { Hypocomplementic urticarial vasculitis } \\ & \text { Idiopathic chronic urticaria } \\ \text { Other } & \text { Delayed pressure urticaria } \\ & \text { Cryoglobulinemia } \\ & \text { Behçet's disease } \\ \text { Mastocytosis }\end{array}$

Modificated and update from: (Affleck and Littlewood 2005; Koning et al. 2007; Kyle and Rajkumar 2003; Csepregi and Nemesánszky 2000; Davis and Brewer 2004; Hawkins et al. 2004; Tomkova et al. 1998; Zuberbier et al. 2009; Deacock 2008) 
et al. 1991; Ohta et al. 1987; Wouters and van de Putte 1986). Leucocytosis is the result of a striking neutrophilia that is probably secondary to bone marrow granulocyte hyperplasia (Pouchot et al. 1991 and Min et al. 2003). In a series of 62 patients, $50 \%$ of the patients had peripheral leucocyte counts $\geq 15.000 \mathrm{~mm}^{3}$, and $37 \%$ had white blood cell counts $\geq 20.000 \mathrm{~mm}^{3}$ (Sari et al. 2009). Krumbhaar introduced the term "leukemoid reaction" in 1926 to describe leukocytic features that could mimic leukemia and that included both leukocytosis and leukopenia and it can be associated with various leukocyte types -neutrophils, lymphocytes, monocytes, eosinophils, and basophils- have been described (Krumbhaar 1926 and Sakka et al. 2006). Persistent neutrophilic leukocytosis above 50,000 cells $/ \mu \mathrm{L}$ when the cause is other than leukemia defines a LR The diagnostic work-up consists of the exclusion of chronic myelogenous leukemia and chronic neutrophilic leukemia and the detection of an underlying cause as severe infections, intoxications, malignancies, severe hemorrhage, or acute hemolysis (Sakka et al. 2006). In this case the initial presentation included a LR and our initial investigations were directed to the differential diagnosis who was verified by a combination of the following: (i) a complete blood count with a peripheral blood smear that shows marked mature neutrophilia with a left shift; (ii) a high leukocyte alkaline phosphatase score; (iii) hypercellular bone marrow with intact maturation and morphology of all the elements; (iv) the absence of cytogenetic abnormalities by cytogenetic-molecular studies; (v) a mature granulocyte pattern by immunophenotyping of peripheral blood and bone marrow (Min et al. 2003).

Although LR is a rare manifestation of AOSD it has been described in the context of Fever of Uncertain Origin (FUO) (Crispin et al. 2005) and in our patient it was one of the initial diagnosis. We initially thought in AOSD after a systematic approach as we exposed before and after excluding infections, malignances and rheumatic diseases. After this work-up we applied the Yamaguichi (Yamaguchi et al. 1992) criteria and also the clinical scale designed recently by Crispin and colleagues (Crispin et al. 2005) particularly because of the initial diagnosis of FUO. Our patient met the Yamaguchi criteria for AOSD and also had a Crispin score $\geq 30$. In support of the diagnosis of AOSD was the high serum ferritin: $1650 \mu \mathrm{g} / \mathrm{L}$ it remained eight times the top limit of normally during the acute phase (2 weeks). Although raised serum ferritin is not in the Yamaguchi criteria, it is regarded as a very useful tool in assisting the diagnosis of AOSD (Fautrel 2002) and ferritin levels in AOSD are usually higher than those found in patients with other autoimmune or inflammatory diseases. The validity of hyperferritinaemia as a diagnostic tool was evaluated in the retrospective study by Fautrel with 49 patients, where a fivefold increase in serum ferritin had $80 \%$ sensitivity and $41 \%$ specificity and similarly a Japanese study (Yamaguchi et al. 1992), with $82 \%$ sensitivity and $46 \%$ specificity. In this case we supported the diagnosis of AOSD based on exclusion diagnosis, clinical and paraclinical criteria.

The cause of the pulmonary hemorrhage and atypical rashes in our patient and other case reports is unclear, although proinflammatory cytokines are thought to be involved. Overproduction of interleukin (IL)-18 appears to be an important cytokine in AOSD as it is overproduced in the acute phase of the disease and with serum levels of soluble IL-2 receptors (sIL-2R) may be used as a marker for monitoring disease activity (Clio et al. 2012). Serum levels of IL1B, IL-17 and IL-6 may be potential markers for disease activity and useful for monitoring the efficacy of treatment. Otherwise, IL8 is more related to the prediction of persistent arthritis but not of disease activity. The Interferon- $\gamma$ (IFN- $\gamma$ ) and tumor necrosis factor- $\alpha$ serum concentrations are elevated in AOSD patients without correlation with disease activity (Clio et al. 2012). Arndt and colleagues suggest that, in animal models endotoxemia-related lung injury was associated with increased IL-18 levels in both blood and lung tissue, and this could explain in part a possible relationship of pulmonary hemorrhage and IL-18 (Arndt et al 2000).

\section{Conclusions}

We present a rare case of AOSD with unusual manifestations. To the best of our knowledge, this is the first case reported before of AOSD with an acute presentation as pulmonary hemorrhage, and the second case reported before as angioedema and urticaria as initial presentation. This is the only case reported the combination of these atypical features. We suggest to the clinicians to keep in mind these findings and emphasize the need to consider urticaria and angioedema in the differential diagnosis of cutaneous manifestations of AOSD and recognize this new finding of pulmonary hemorrhage as another possibility in the differential diagnosis of infiltrates in acute AOSD.

\section{Ethical standards and consent}

This study was approved by the Institutional Ethical Committee of our Hospital; Hospital Militar Central. All techniques were performed according to the Helsinki declaration of 1975 and its modifications. Additionally, informed consent was obtained from the patient and any accompanying images for being included in the study.

Competing interests

The authors declare that they have no competing interests.

\section{Authors' contributions}

SM and DC carried out the literature review and wrote case report of "Acute adult-onset still's disease presenting as pulmonary hemorrhage, urticaria, 
angioedema and leukemoid reaction: a case report and literature review". RV and JV contributed to revising the manuscript. GQ performed the data and image gathering as well as in the revising the manuscript. All authors read and approved the final manuscript.

\section{Acknowledgements}

We have not received any funding from any institution for this work.

\section{Author details}

${ }^{1}$ Rheumatology Unit, Department of Internal Medicine, Hospital Universitario De La Samaritana E.S.E, Bogotá, Colombia. ${ }^{2}$ Rheumatology Unit, Department of Internal Medicine, Universidad de La Sabana, Hospital Universitario de La Samaritana E.S.E, Bogotá, Colombia. ${ }^{3}$ Department of Rheumatology, Universidad de La Sabana, Bogotá, Colombia. ${ }^{4}$ Division of Rheumatology, Department of Internal Medicine, Hospital Militar Central, Bogotá, Colombia. ${ }^{5}$ Division of Rheumatology, Department of Internal Medicine, Universidad Nacional de Colombia, Hospital Universitario Fundación Santa Fe, Bogotá, Colombia. ${ }^{6}$ Clinical Rhematology Research Fellow, Rheumatology Unit, Hospital Universitario De La Samaritana E.S.E, Cra 18A \# 10 - 25 sur, Bogotá, Colombia.

Received: 28 February 2015 Accepted: 13 March 2015 Published online: 10 April 2015

\section{References}

Affleck AG, Littlewood SM (2005) Adult-onset Still's disease with atypical cutaneous features. J Eur Acad Dermatol Venereol 19(3):360-363

Arndt PG, Fantuzzi G, Abraham E (2000) Expression of interleukin-18 in the lung after endotoxemia or hemorrhage-induced acute lung injury. Am J Respir Cell Mol Biol 22:708-713

Bywaters EGL (1971) Still's disease in the adult. Ann Rheum Dis 30(2):121-133

Cheema GS, Quismorio FP Jr (1999) Pulmonary involvement in adult-onset Still's disease. Curr Opin Pulm Med 5(5):305-309

Clio P. Mavragani, Evangelos G. Spyridakis, and Michael Koutsilieris (2012) Adult-Onset Still's Disease: From Pathophysiology to Targeted Therapies. Int J Inflam. doi:10.1155/2012/879020

Criado RF, Criado PR, Vasconcellos C, Szajubok JC, Michalany NS, Kadunc BV, Costa Martins JE (2006) Urticaria as a cutaneous sign of adult-onset Still's disease. J Cutan Med Surg 10(2):99-103

Crispin JC, Martinez-Banos D, Alcocer-Varela J (2005) Adult-onset Still disease as the cause of fever of unknown origin. Medicine 84:331-337

Csepregi A, Nemesánszky E (2000) Acquired C1 esterase inhibitor deficiency. Ann Intern Med 133(10):838-839

Davis DP, Brewer JD (2004) Urticarial vasculitis and hypocomplementemic urticarial vasculitis syndrome. Immunol Allergy Clin North Am 24(2):183-213

Deacock SJ (2008) An approach to the patient with urticaria. Clin Exp Immunol 153(2):151-161

Fautrel B (2002) Ferritin levels in adult Still's disease: any sugar? Joint Bone Spine 69:355-357

Gesierich A, Stoevesandt J, Kneitz C, Bröcker EB, Schön MP (2009) Adult-onset Still's disease: an uncommon differential diagnosis of urticaria and treatment with anakinra. J Eur Acad Dermatol Venereol 23(1):104-106

Hawkins PN, Lachmann HJ, Aganna E, McDermott MF (2004) Spectrum of clinical features in Muckle-Wells syndrome and response to anakinra. Arthritis Rheum 50(2):607-612

Kadar J, Petrovicz E (2004) Adult-onset Still's disease. Best Pract Res Clin Rheumatol 18(5):663-676

Koning HD, Bodar EJ, van der Meer JW, Simon A, Schnitzler Syndrome Study Group (2007) Schnitzler syndrome: beyond the case reports: review and follow-up of 94 patients with an emphasis on prognosis and treatment. Semin Arthritis Rheum 37(3):137-148

Kozel MM, Sabroe RA (2004) Chronic urticaria: aetiology, management and current and future treatment options. Drugs 64(22):2515-2536

Krumbhaar EB (1926) Leukemoid blood pictures in various clinical conditions. Am J Med Sci 172:519-533

Kyle RA, Rajkumar SV (2003) Monoclonal gammopathies of undetermined significance: a review. Immunol Rev 194:112-139

Lee JY, Yang C, Hsu MM (2005) Histopathology of persistent papules and plaques in adult-onset. Still's disease J Am Acad Dermpath 52(6):1003-1008
Masson C, Le Loet X, Liote F, Dubost JJ, Boissier MC, Perroux-Goumy L, Bregeon C, Audran M (1996) Comparative study of 6 types of criteria in adult Still's disease. J Rheumatol 23(3):495-497

Min JK, Cho CS, Kim HY, Oh EJ (2003) Bone marrow findings in patients with adult Still's disease. Scand J Rheumatol 32:119-121

Ohta A, Yamaguchi M, Kaneoka H, Nagayoshi T, Hiida M (1987) Adult Still's disease: review of 228 cases from the literature. J Rheumatol 14(6):1139-1146

Pouchot J, Sampalis JS, Beaudet F, Carette S, Decary F, Salusinsky-Sterrnbach M, Hill RO, Gutkowsky A, Hard M, Myhal D, Senecal JL, Yeadon C, Esdaile JM (1991) Adult Still's disease: manifestations, disease course, and outcome in 62 patients. Medicine (Baltimore) 70(2):118-136

Prendiville JS, Tucker LB, Cabral DA, Crawford RI (2004) A pruritic linear urticarial rash, fever, and systemic inflammatory disease in five adolescents: adultonset still disease or systemic juvenile idiopathic arthritis sine arthritis? Pediatr Dermatol 21(5):580-588

Sakka V, Tsiodras S, Giamarellos-Bourboulis EJ, Giamarellou H (2006) An update on the etiology and diagnostic evaluation of a leukemoid reaction. Eur J Intern Med 17:394-398

Salaffi F, Filosa G, Bugatti L, Maestrini MD (2009) Urticaria as a presenting manifestation of adult-onset Still's disease. Clin Rheumatol 19(5):389-391

Sari I, Birlik M, Binicier O, Akar S, Yilmaz E, Onen F, Akkoc N (2009) A case of adult-onset Still's disease complicated with diffuse alveolar hemorrhage. J Korean Med Sci 24(1):155-157

Setterfield JF, Hughes GRV, Kobza-Black A (1998) Urticaria as a presentation of adult Still's disease. Br J Dermatol 138(5):906-908

Soy M (2004) A case of adult-onset Still's disease presenting with angioedema. Clin Rheumatol 23(1):92

Tomkova H, Shirafuji Y, Arata J (1998) Schnitzler's syndrome versus adult onset Still's disease. Eur J Dermatol 8(2):118-121

Wouters JM, van de Putte LB (1986) Adult-onset Still's disease; clinical and laboratory features, treatment and progress of 45 cases. Q J Med 61(235):1055-1065

Yamaguchi M, Ohta A, Tsunematsu T, Kasukawa R, Mizushima Y, Kashiwagi H, Kashiwazaki S, Tanimoto K, Matsumoto Y, Ota T, Akisuki M (1992) Preliminary criteria for classification of adult Still's disease. J Rheumatol 19:424-430

Zendee RM, Elaba P, Ocampo A (2004) Urticaria and adult-onset still's disease. J Am Acad Dermatol 50(3)(Supplement 1):59

Zuberbier T, Asero R, Bindslev-Jensen C, Walter Canonica G, Church MK, GiménezArnau A, Grattan CE, Kapp A, Merk HF, Rogala B, Saini S, Sánchez-Borges M, Schmid-Grendelmeier P, Schünemann H, Staubach P, Vena GA, Wedi B, Maurer M (2009) EAACI/GA(2)LEN/EDF/NAO guideline: definition, classification and diagnosis of urticaria. Allergy 64(10):1417-1426

\section{Submit your manuscript to a SpringerOpen ${ }^{\circ}$ journal and benefit from:}

- Convenient online submission

- Rigorous peer review

- Immediate publication on acceptance

- Open access: articles freely available online

- High visibility within the field

- Retaining the copyright to your article

Submit your next manuscript at springeropen.com 